ear against the back of the violin and playing a scale on the pianoforte. Ellis (loc. cit. footnote) gives details of elaborate tests made by sounding tuningforks over the $\int$ holes of a number of the best and oldest violins. There were at least two maxima in all cases, but the best specimens gave almost equal response to his forks from 240 to 560 , and in the case of Dr. Huggins's Stradivari of 1708 , described as one of the best Stradivari, " every fork was more or less reinforced; there was a subordinate maximum at 252 ; a better at $260-268$ vib. ; very slight maxima at $312,348,384,4$ I2 420,428 (the last of which was the best, but was only a fair reinforcement), 472-48o, but 520 was decidedly the best and 540 good. No one fork was reinforced to the extent it would have been on a resonator properly tuned to it, but no one note was deteriorated."

The peculiar shape of the body of a violin is such as to give double resonance even if the walls were rigid. Taking into account the vibrations of the wooden walls as well, we have a multiple resonator which will no doubt give an even response over a wide range in the best violin.

Just as Sir Richard Paget's double resonator modifies an artificial larynx to give vowel sounds, so the multiple resonator--the violin body-determines the valued quality of tone of the violin.

Multiple resonance gives promise of being a very fruitful field of research in acoustics.

Signals Experimental Establishment

P. Rothwell.

Woolwich Common, S.E.I8, January I5.

\section{Destruction of the Polarisation of Resonance Radiation by weak Magnetic Fields.}

THE earlier studies of the resonance radiation of mercury vapour in exhausted quartz tubes by one of the present writers showed no traces of polarisation, even when the exciting light was polarised.

Recent experiments by Lord Rayleigh apparently indicated that polarisation existed in that part of the excited column at some little distance from the window at which the beam entered; in other words, when the excitation was produced by light from which the core of the 2536 line had been removed by absorption. This observation was not verified in experiments made by one of us last spring and published in a recent number of the Philosophical Magazine. The polarisation was found to be strong and of uniform percentage right up to the window at which the beam entered.

On commencing a further study of the phenomenon we found it impossible to produce as strong polarisation as was indicated by the earlier experiments, and after varying the conditions in every conceivable manner we finally found that the disturbing factor was the magnetic field of the earth, the polarisation rising to a very high value (90 per cent.) when the magnetic field of the earth was compensated by a large solenoid carrying a feeble, current. In the absence of the solenoid the percentage of polarisation dropped to fifty or less.

This appears to be a new magneto-optic effect, and is manifested only when the magnetic field is parallel to the magnetic vector of the exciting light and perpendicular to the beam of exciting rays. A field of only five or six times the strength of the earth's field practically destroys the polarisation. Discrepancies found previous to the discovery of this effect were due to the fact that in some cases the apparatus faced north and south, and in others east and west. Lord Rayleigh's observation was doubtless due to the stray field of the electro-magnet which was used to flatten the discharge against the wall of his quartz lamp.

R. W. WOOD,

Baltimore, Jan. 25. Alexander Ellet.

\section{Volcanic Activity in Iceland and Long Distance Transport of "Dust."}

With reference to the communication on this subject made by Prof. Grenville Cole to NAture, November II, I922 (vol. IIO, p. 635), the following additional remarks may be of interest.

In the Deutsche Fisherei Zeitung for November I4, I922, occurs a note which may be summarised as follows: A Geestemunde steam trawler, the Tyr, while returning from her last trip to Iceland, experienced a fall of ashy material on her deck. This occurred while at a distance of at least 400 sea miles from Iceland. It is stated that the material was doubtless from Hecla, and though no date of the occurrence is given, it is known that the vessel made Geestemunde on October 25. A communication from the British Consul at Thorshavn also deals with this matter, and reads as follows :

". . . beg to inform you that on October 6 this sandstorm was observed on these islands. The weather was fine that day, but clouded, and the sky had a red-grey colour, and I remember the feeling of getting fine sand in my eyes while being in a rowing boat that morning, and going home to lunch my wife showed me some fine dark grey sand lying in the windows, which had been open that morning.

"I may add that a telegram received from Iceland that day gave the news of volcanic eruption in Iceland."

For these two reports I am indebted to Mr. G. T. Atkinson, district inspector of fisheries, Eastern Area.

Ministry of Agriculture and Fisheries, Fisheries Laboratory, Lowestoft.

\section{The Wegener Hypothesis and the Origin of the Oceans.}

READERS of NATURE have been served with good reviews and discussions on the Wegener hypothesis, and it may therefore be of interest to point out that, so far as it relates to the origin of the Atlantic Ocean, this hypothesis was anticipated by previous writers, more especially by Osmond Fisher and W.H. Pickering. Fisher's views are well known to students of geodynamics, and Wegener himself refers to papers by W. H. Pickering and F. B. Taylor; but only by reading the accounts given by these authors can one realise how completely they forestalled Wegener, so far as the origin of the Atlantic by the westerly drift of the Americas is concerned.

It was to accommodate Sir George Darwin's views on the origin of the moon that Osmond Fisher suggested, first in NATURE (r882, vol. 25, p. 243) and afterwards in the second edition of his "Physics of the Earth's Crust," that the Pacific Ocean is a scar and depression on the earth's surface, left by the detachment of the moon. The following are Fisher's words (p. 380) : "The hole would be filled up by the influx of the molten substratum from beneath and around. The remaining crust would separate into larger and smaller fragments, and partly float towards the cavity. Thus when the 